\title{
Tip of Peritoneal Catheter of Ventriculo- Peritoneal Shunt in Scrotum
}

\author{
Seyed Amir Javadi, ${ }^{1, *}$ and Fereshteh Naderi ${ }^{2}$ \\ ${ }^{1}$ Neurosurgery Department, Tehran University of Medical Sciences, Tehran, Iran \\ ${ }^{2}$ Neurology Department, Alborz University of Medical Sciences, Karaj, Iran \\ "Corresponding author: Seyed Amir Javadi, Neurosurgery Department, Imam Khomeini Hospital, Keshavarz Blvd, Tehran, Iran. Tel: +98-9126049012, E-mail: \\ javadi1978@yahoo.com
}

Received 2017 July 21; Accepted 2017 July 24.

Keywords: Hydrocephalus, Shunt, Peritoneal, Catheter, Scrotum

\section{Dear Editor,}

A ten-month male infant referred at emergency room with enlargement and fluid accumulation in right scrotum without any history of epididymitis or orchitis. Patient had a history of V-P shunt surgery two months earlier. At physical examination, no sign of hydrocephalus or fever was detected. However, a hard substance could be palpated at scrotum. Ultrasonography detected CSF hydrocele with echogenic tip of peritoneal catheter in right scrotum passing through inguinal canal without any sign of intestinal hernia. Radiologic assessment indicated radioopaque catheter at pelvic area (Figure 1). CSF analysis detected no bacteria and the CSF profile, CBC and urine analyses were normal. The patient underwent direct repair of patent processus vaginalis and repositioning of catheter into peritoneum. Hydrocele improved at early postoperative period and the 6 months follow up outcome was excellent.

A total of 30 cases of peritoneal shunt displacement into scrotum are reported in literature (1); their pattern follows the time course of patent processus vaginalis (PPV) which remains patent up to $60 \%$ of neonates during the first year of life $(1,2)$. The residual peritoneal cavity correlates with body surface, therefore younger pediatric patients have a higher tendency to have V-P shunt distal catheter migrate into the scrotum due to patent processus vaginalis and smaller peritoneal cavity (3).

The most suggested and acceptable treatment for such pediatric cases is direct repair of PPV and ligation of the sac, since increased CSF pressure prevents spontaneous occlusion of PPV (2-5). Some even suggest assessment and prophylactic repair of the other side, when applicable. Early and accurate intervention could prevent further complications and make significant improvements. Laparoscopic approach has been shown to be associated with a lower rate of malposition, distal obstruction and distal shunt failure $(2,6,7)$.

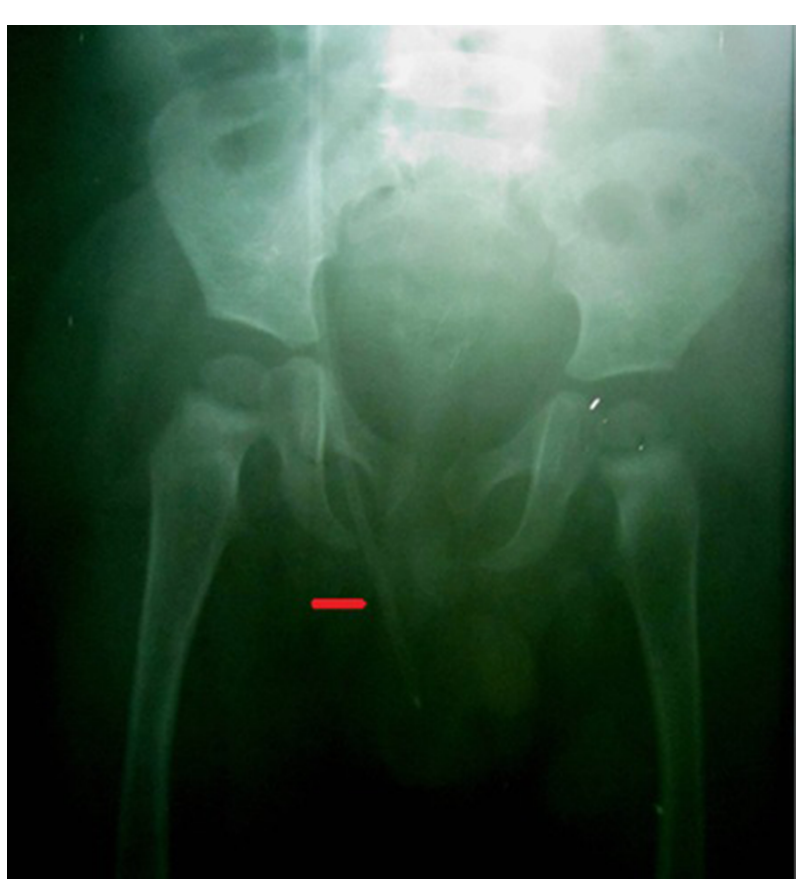

Figure 1. X-ray of peritoneal catheter displacement into scrotum through inguinal canal; red pointer indicates opaque peritoneal catheter.

\section{References}

1. Mohammadi A, Hedayatiasl A, Ghasemi-Rad M. Scrotal migration of a ventriculoperitoneal shunt: a case report and review of literature. Med Ultrason. 2012;14(2):158-60. [PubMed: 22675718].

2. Ricci C, Velimirovic BM, Fitzgerald TN. Case report of migration of 2 ventriculoperitoneal shunt catheters to the scrotum: Use of an inguinal incision for retrieval, diagnostic laparoscopy and hernia repair. Int J Surg Case Rep. 2016;29:219-22. doi: 10.1016/j.ijscr.2016.11.002. [PubMed: 27883967].

3. Oktem IS, Akdemir H, Koc K, Menku A, Tucer B, Selcuklu A, et al. Migration of abdominal catheter of ventriculoperitoneal shunt into the scrotum. Acta Neurochir(Wien). 1998;140(2):167-70. [PubMed: 10398996].

4. Ozveren MF. Migration of the abdominal catheter of a ventriculoperitoneal shunt into the scrotum. Neurol Med Chir. 1999;39(4):313-5. 
5. Hung SW. A 5-month-old infant with right scrotum swelling; a case report. Emerg. 2017;5(1):14.

6. Phan S, Liao J, Jia F, Maharaj M, Reddy R, Mobbs RJ, et al. Laparotomy vs minimally invasive laparoscopic ventriculoperitoneal shunt placement for hydrocephalus: A systematic review and meta-analysis. Clin Neurol Neurosurg. 2016;140:26-32. doi: 10.1016/j.clineuro.2015.10.025.
[PubMed: 26615465]

7. Svoboda SM, Park H, Naff N, Dorai Z, Williams MA, Youssef Y. Preventing Distal Catheter Obstruction in Laparoscopic Ventriculoperitoneal Shunt Placement in Adults: The "Falciform Technique". J Laparoendosc Adv Surg Tech A. 2015;25(8):642-5. doi: 10.1089/lap.2015.0196. [PubMed: 26186206]. 